\title{
The Relationship between Mindfulness and Quality of Life on Pregnant Mothers
}

\author{
Endang Fourianalistyawati ${ }^{1}$ \\ \{endangfouriana@gmail.com ${ }^{1}$ \} \\ Universitas YARSI Fakultas Psikologi, Cempaka Putih, Jakarta Pusat ${ }^{1}$
}

\begin{abstract}
Pregnant mothers tend to experience biological changes during their pregnancy. The changesin their biological conditions can cause health problems and negative impact on their quality of life. Previous research studiesindicate that mindfulness-based interventions can overcome some physical and psychological problems in pregnant women, such as nausea, pain, stress, and depression. Therefore,this research aimed to explore the relationship between mindfulness and quality of life on pregnant mothers. The result of the study can be a resource for next study on intervention for pregnant mothers in Indonesia to help them improve their quality of life. Respondents were 127 pregnant mothers who were domiciled in Indonesia. This study used Five Facets of Mindfulness Questionnaire (FFMQ) to measure mindfulness, and EQ-5D5L to measure the quality of life. The results of this study showed that the dimensions of acting with awareness and non-judging have a significant relationship with several dimensions in quality of life.
\end{abstract}

Keywords: Mindfulness, Quality of Life, Pregnant Mothers.

\section{Introduction}

Pregnancy is a natural event and also a moment that determines the next life. Women must adapt to biological and psychological changes that occur during pregnancy. The changes that occur within the self can be the precipitating event of various psychological reactions, from mild emotional reactions to the level of severe mental disorders.Pregnant women usually feel nausea, vomiting, fever and weak. Nausea and vomitingcan be reduced until the first trimester ends. In the second trimester, the bodybegins to adapt, and nausea and vomiting also diminish. However, in the third trimester, complaints caused by stomach enlargement, anatomical changes, and hormonal changes cause the emergence of complaints in pregnant women [1].

Health problems in pregnant women, both physically and psychologically, have an impact on the quality of life. Women have a condition that can increase the risk during pregnancy, about 5-10\% of pregnancies including high-risk pregnancies [2]. Women with high-risk pregnancies need to be preparedfor the unexpected situation during their pregnancies and laboring process. Through improvements in health conditions that have a direct impact on quality of life, $90-95 \%$ of pregnant women including high-risk pregnancies can deliver their babies safely and finally get healthy babies. High-risk pregnancies can be prevented and treated well if symptoms are found as early as possible [2].

A study showed improvements on the well-being of pregnant women by providing mindfulness-based interventions, particularly in overcoming pain, reducing depression, and 
increasing the ability of parents to give full attention to their newborns [3]. Mindfulness is the ability to be aware of and focus on the current experience of the individual, both internal and external [4]. In contrast to other relaxation techniques, mindfulness develops the individual's ability to pay attention to the current conditions, without changing the state of [5]. Althoughrelaxation techniques can help reduce stress on pregnant women, mindfulness meditation has more benefits as it can reduce dysfunctional thoughts and distractions [6].

Research related to mindfulness and quality of life has been done in Indonesia. However, no one has examined the mindfulness and quality of life using pregnant women as a subject. Meanwhile, pregnant women and their children are still one of the focuses to be helped in Indonesia, since there are still many of them have a low quality of life. Hence, the researcher was interested to examine more about the relationship between mindfulness with the quality of life in pregnant women in Indonesia.

\subsection{Mindfulness}

Mindfulness is an open consciousness and a condition of attention to what is happening right now [4]. The definition of mindfulness is "awareness of present experience, with acceptance" [7]. Mindfulness is the condition ofindividual who consciously brings his experience to the current state with a full sense of openness as well asa sense of acceptance. Mindfulness brings the awareness of the individual to focus on the goal, by non-judging attitude and by not avoiding conditions that cannot be mastered [8],[9]. Being mindful means that the individual is aware of whatever his current condition is, regardless of past and future events [10].

Mindfulness in pregnant women can help reducing the stress of pregnancy, reducing pain or pain in body parts such as feet, head, muscle and help controlling nausea. Not only help during pregnancy, but mindfulness also helps pregnant women to passtheir laboring time that is full of contractions and pain. Pregnant women can also pass through the process of pregnancy and childbirth calmer and more aware [11].

The measuring tool for this researchis Five Facets of Mindfulness Questionnaire (FFMQ) developed by Baer, Smith, Lykins, Button, Krietemeyer, Sauer, Walsh, Duggan, and Williams [12]. The FFMQ is multidimensional and has five dimensions that can be used separately or completely. These dimensions are: observing, it means to be aware of internal and external stimulus, such as sensation, emotion, cognition, sight, hearing, and smell; describing, that it mentions or mentally labels that stimulus with words; acting with awareness that is aware of the action being performed compared to acting automatically or without thinking; non-judging of inner experience that is moving away from the mind to evaluate sensation, cognition, and self-emotion; non-reactivity to inner experience is to allow the thoughts and feelings to come and go, without giving the more attention given to them.

\subsection{Quality of Life}

Quality of life is a balance between opportunity or limitation of life, which is the result of the process of interaction between individuals and their environment [13]. Felce and Perry (1995) suggest the quality of life as overall wellbeing comprised of objective and subjective evaluations [13]. This evaluation consists of physical, material, social, and emotional wellbeing, along with a person's level of development. Nagler (1996), suggests that quality of life is a general concept of superior meaning that can be applied to the life of a person as a whole. Quality of life is then defined as how perfect or superior the life as a whole [13]. 
Quality of life is the overall well-being of life which includes objective and subjective evaluation. Objective evaluation refers to the individual living conditions that can be seen and proven such as health, material income, quality of life at home, friendship relationships, activities, and social roles. Subjective evaluation refers to personal satisfaction with the condition of life. Both types of evaluation can be detailed in a physical, social, emotional, and material perspective. The physical evaluation includes health, safety, mobility, and freshness. Material evaluation, including finance, income, various aspects of the living environment, transportation, security, and tenure. Social evaluation- including deep interpersonal relationships- is the provision of support between himself and friends, family, and community involvement.The emotional evaluation includes stress affection, mental level, self-esteem, respect, and faith in religion [14].

Individual's quality of life depends on how he or she values whole-life experiences, positive or negative [15]. Each has a different quality of life depending on the interpretation of each. Good quality of life for some individuals is judged by work, family and [16]. It is influenced by eight factors: control, potential opportunities, resources, system support, skills, events in life, political change, and environmental change [13]. According to WHOQOL [17], the quality of life is divided into six categories, namely:

1) Physical health aspects, related to pain or pain, discomfort, energy and fatigue, sleep and rest.

2) Psychological aspects, associated with positive and negative feelings, self-esteem, thinking, memory, learning and concentration, views of body and appearance.

3) The level of independence aspects, associated with daily activities such as the ability to maintain and take care of oneself, mobility, as well as about treatment and dependence on one treatment or treatment, and work ability.

4) Social relations aspects. Included in this aspect are personal relationships, social support, and sexual activity.

5) Environmental aspects. These aspects include freedom, physical safety, security, residential environments, financial resources, opportunities for new information and skills, participation in leisure activities at leisure, physical environment (including pollution, noise, traffic), and transportation.

6) Spirituality aspects, religion and personal beliefs.

Measuring tool used to measure the quality of life in this research is EQ-5D5L developed by EuroQoL Group. EQ-5D5L has five dimensions of health status aspects, namely mobility, self-care, usual activities, pain/discomfort, and anxiety/depression. Each dimension consists of five choices of answers, i.e., level 1 to level 5, which indicates the severity of the condition. The combination of five-digit levels of each dimension establishes a person's health status. A scale to measure the health condition of the person based on his perception or self-rating is included at the end of the EQ-5D5L. The scale range is $0-100.0$ is the worst health status he can think and 100 is the best health status he can think. In this study, EQ-5D5L has been adapted into Indonesian by researchers from Padjadjaran University and YARSI University Jakarta [18].

\subsection{Pregnant Mothers}

The selection of pregnant mothers as the subject focus in this study is based on the notion that pregnant women are susceptible to various physical and psychological problems affecting the quality of life in their pregnancy, and pregnancy is a long-awaited period for most women, therefore it is important to keep pregnant women in healthy condition, physically and 
psychologically. In Jakarta, the mortality rate of pregnant women is still quite high. Data from Maternal Health Report 2012 by Health Department of DKI Jakarta Province explained, from 6 districts or cities in Jakarta Capital City, the highest number of deaths occurred in East Jakarta, 34 pregnant women from 88 health centers.

\section{Methods}

\subsection{Participants}

Participants in this research were determined using purposive sampling technique. The number of respondents were 127 pregnant women and domiciled in Indonesia. The giving of questionnaires was done online.

\subsection{Data Collection Instruments}

To find out the level of mindfulness of the individual in this case as one of the variables to be correlated, the data collection tool used was FFMQ questionnaire [12]. FFMQ used has been adapted into Indonesian. FFMQ has 39 items representing five dimensions, namely observing, describing, acting with awareness, nonjudging of inner experience, and nonreactivity to inner experience. This scale uses a Likert scale ranging from 1 (never) to 5 (always).

Quality of life on pregnant women, in this case, was measured by using EQ-5D5L. EQ5D5L is widely used to knowthe health-related quality of life. This scale has been adapted into Indonesian by researchers from Padjadjaran University and YARSI University Jakarta. EQ5D5L consists of 5 questions representing five aspects of the problem on individual health, namely mobility, self-care, usual activities, pain, and anxiety. Each question consists of 5 choices of answers, i.e., no problems (level 1) until the problem is severe (level 5). Also, at the end of the scale, there is a question about how well the participant's health status is based on his perceptions. The answer option consists of a scale of 0-100. A score of 0 reflects the worst health conditions and the 100 best health conditions imaginable.

\subsection{Data Analysis}

The data obtained from this research were analyzed by using bivariate analysis with product moment correlation, to see whether there was significantcorrelation between mindfulness and depression inthe pregnant mother.

\section{Results}

\subsection{Demographic Overview of Study Respondents}

Here is a demographic overview of the study respondents: 
Table 1. Participants’ Demographic Data.

\begin{tabular}{|c|c|c|c|}
\hline & Variable & Amount & Percentage \\
\hline \multirow{2}{*}{ Age } & $17-34$ years old & 114 & $89.8 \%$ \\
\hline & $\geq 35$ years old & 13 & $10.2 \%$ \\
\hline \multirow{2}{*}{ Work } & Not Working & 58 & $45.7 \%$ \\
\hline & Working & 69 & $54.3 \%$ \\
\hline \multirow{6}{*}{ Education } & Elementary School & 1 & $0.8 \%$ \\
\hline & Junior High School & 1 & $0.8 \%$ \\
\hline & Diploma 1-Diploma 3 & 36 & $28.3 \%$ \\
\hline & S1 & 71 & $55.9 \%$ \\
\hline & S2 & 16 & $12.6 \%$ \\
\hline & S3 & 2 & $1.6 \%$ \\
\hline \multirow{8}{*}{ Domicile } & Sumatra & 81 & $63.8 \%$ \\
\hline & Java & 32 & $25.2 \%$ \\
\hline & Kalimantan & 3 & $2.4 \%$ \\
\hline & Sulawesi & 6 & $4.7 \%$ \\
\hline & NTB & 2 & $1.6 \%$ \\
\hline & NTT & 1 & $0.8 \%$ \\
\hline & Bali & 1 & $0.8 \%$ \\
\hline & Papua & 1 & $0.8 \%$ \\
\hline \multirow{3}{*}{ Marital Status } & Not Married & 1 & $0.8 \%$ \\
\hline & Married First & 124 & $97.6 \%$ \\
\hline & Marrying Back & 2 & $1.6 \%$ \\
\hline \multirow{5}{*}{ Expense } & $<$ Rp. 1.000 .000 & 13 & $10.2 \%$ \\
\hline & Rp. 1.000 .000 - Rp. 3.000 .000 & 66 & $52 \%$ \\
\hline & Rp. 3.000 .000 - Rp. 5.000 .000 & 28 & $22 \%$ \\
\hline & Rp. 5.000 .000 - Rp. 7.000 .000 & 6 & $4.7 \%$ \\
\hline & $>$ Rp. 7.000 .000 & 14 & $11 \%$ \\
\hline
\end{tabular}

The study respondents were mostly $17-34$ years old $(89.8 \%)$, worked $(54.3 \%)$, had latest education at S1 (55.9\%), domiciled in Sumatra (63.8\%), lived the first marriage (97.6\%), and has an average expenditure of Rp. 1,000,000 - Rp. 3,000,000 (52\%).

\subsection{Mindfulness of Study Respondents}

Here is a picture of the mindfulness of the study respondents:

Table 2. Mindfulness Views of Participants.

\begin{tabular}{ccccc}
\hline Dimension & Minimum Value & Maximum Value & Mean & Standard Deviation \\
\hline Observing & 13 & 37 & 24.89 & 4.953 \\
Describing & 14 & 40 & 27.43 & 5.446 \\
Acting with Awareness & 16 & 40 & 28.64 & 4.890 \\
Non-Reactivity & 10 & 35 & 20.61 & 3.688 \\
Non-Judging & 13 & 40 & 25.78 & 5.348 \\
\hline
\end{tabular}

The respondents had average scores on observing dimensions of 24.89, 27.43 describing dimensions, acting with awareness of 28.64 , non-reactivity of 20.61 , and non-judging of 25.78 . 


\subsection{The Quality of Life of Participants}

The following is a description of the quality of life of participants in this study:

Table 3. Description of the Participants' Quality of Life.

\begin{tabular}{|c|c|c|c|}
\hline Dimensions of Quality of Life & Level* & Number & Percentages \\
\hline \multirow{5}{*}{ 1. Mobility } & 1 & 95 & $74.8 \%$ \\
\hline & 2 & 27 & $21.3 \%$ \\
\hline & 3 & 4 & $3.1 \%$ \\
\hline & 4 & 1 & $0.8 \%$ \\
\hline & 5 & 0 & $0 \%$ \\
\hline \multirow{5}{*}{ 2. Self-Care } & 1 & 113 & $89 \%$ \\
\hline & 2 & 12 & $9.4 \%$ \\
\hline & 3 & 2 & $1.6 \%$ \\
\hline & 4 & 0 & $0 \%$ \\
\hline & 5 & 0 & $0 \%$ \\
\hline \multirow{5}{*}{ 3. Usual Activities } & 1 & 58 & $45.7 \%$ \\
\hline & 2 & 56 & $44.1 \%$ \\
\hline & 3 & 12 & $9.4 \%$ \\
\hline & 4 & 1 & $0.8 \%$ \\
\hline & 5 & 0 & $0 \%$ \\
\hline \multirow{5}{*}{ 4. Pain/Discomfort } & 1 & 30 & $23.6 \%$ \\
\hline & 2 & 81 & $63.8 \%$ \\
\hline & 3 & 13 & $10.2 \%$ \\
\hline & 4 & 3 & $2.4 \%$ \\
\hline & 5 & 0 & $0 \%$ \\
\hline \multirow{5}{*}{ 5. Depression/Anxiety } & 1 & 48 & $37.8 \%$ \\
\hline & 2 & 60 & $47.2 \%$ \\
\hline & 3 & 14 & $11 \%$ \\
\hline & 4 & 5 & $3.9 \%$ \\
\hline & 5 & 0 & $0 \%$ \\
\hline Combination of Five Aspects & uation 11 & 18 & $14.2 \%$ \\
\hline
\end{tabular}

* Level: 1 = no problem, $2=$ slight problem, $3=$ moderate problems, $4=$ severe problems, $5=$ Unless / extreme problems.

Based on the data in table 3, it shows that $95 \%$ of participants have no problems regarding walking and moving from one place to another. Regarding self-care, $89 \%$ of participants can do it themselves. In daily activities, $45.7 \%$ of participants had no problems. The majority of participants $(63.8 \%)$ in this study felt slight pain/discomfort, and the majority of participants (47.2\%) experienced slight depression/anxiety.

There are $14.2 \%$ of participants who have no problems in all aspects. Individuals can also perceive their health condition by possessing from a range of 0-100 scores, i.e., 0 indicating that their perceived health status is very poor and 100 indicating that their perceived health status is very good. Table 4 shows that the average participant perceives his health status quite well, i.e., $\mathrm{M}=83.06(\mathrm{SD}=10.91)$.

Table 4. Health Description of Participants.

\begin{tabular}{ccccc}
\hline Dimension & Minimum Value & Maximum Value & Mean & Standard Deviation \\
\hline Perception of Health Status & 40 & 100 & 83.06 & 10.914 \\
\hline
\end{tabular}




\subsection{Relationship of Mindfulness and Quality of Life}

Here is a picture of the correlation between mindfulness and quality of life of participants.

Table 5. Spearman's correlation between Mindfulness and Quality of Life.

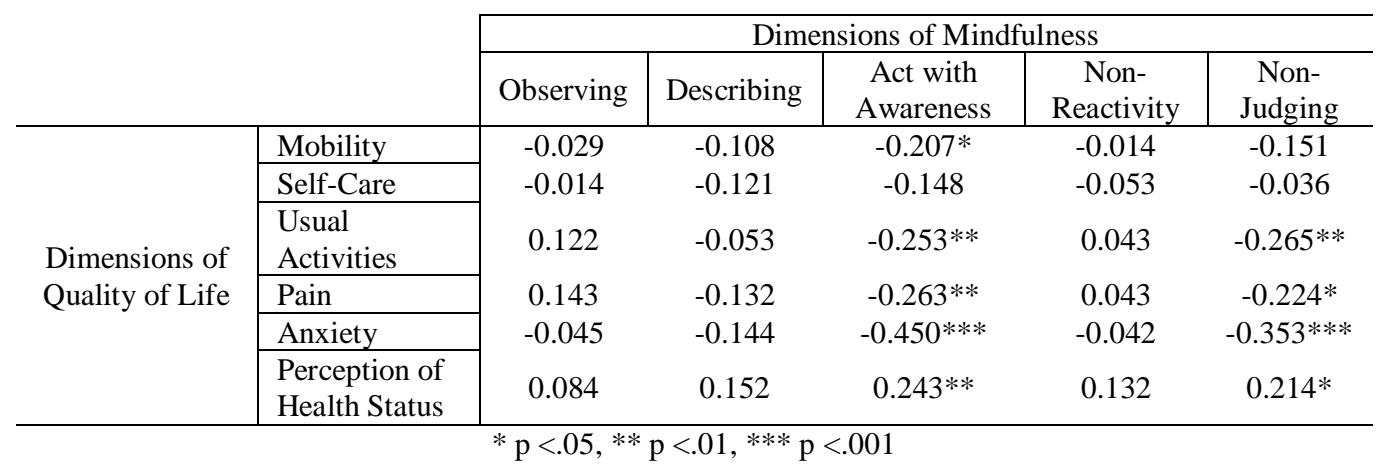

Based on the data in table 5, it shows that there is no significant relationship between observing, describing, non-reactivity dimension on the dimension of mindfulness and quality of life as well as with the health status that participants own perception. The dimensions of acting with awareness in mindfulness have significant relationship with mobility dimensions ( $\mathrm{r}$ $=-0.207, \mathrm{p}<0.05)$, usual activities $(\mathrm{r}=-0.253, \mathrm{p}<0.01)$, pain $(\mathrm{r}=-0.263, \mathrm{p}<0.01)$, and anxiety $(r=-0.450, p<0.001)$ on quality of life. The dimension of acting with awareness also has a significant positive relationship with the perceived health status $(r=0.243, p<0.01)$. The non-judgmental dimension of mindfulness also has significant relationship with several dimensions on quality of life, i.e. usual activities $(r=-0.265, p<0.01)$, pain $(r=-0.224, p$ $<0.05)$, and anxiety $(\mathrm{r}=-0.353, \mathrm{p}<0.001)$. The non-judging dimension also has a positive relationship with perceived health status $(r=0.214, p<0.05)$.

\subsection{Additional Analysis}

In this research, additional analysis is done by doing a t-test on both variables based on demographic data from participants.

\subsubsection{T-Test Results between Demographic Data and Mindfulness Data}

Table 6. T-Test of Demographic and Mindfulness Data.

\begin{tabular}{cc}
\hline $\begin{array}{c}\text { Dimensions of } \\
\text { Mindfulness }\end{array}$ & Marital Status \\
\hline Observing & 0.587 \\
Describing & 0.871 \\
Acting with & 0.011 \\
Awareness & 0.062 \\
Non-Reactivity & 0.790 \\
Non-Judging & \\
\hline
\end{tabular}


In table 6 , it shows that there is a difference of score on the dimensions of acting with awareness in mindfulness-based on marital status.

\subsubsection{T-Test Results from Demographic Data and Quality of Life Data}

Table 7. T-Test of Demographic Data and Quality of Life Data.

\begin{tabular}{lcc}
\hline $\begin{array}{c}\text { Dimensions of Quality of } \\
\text { Life }\end{array}$ & Education & Domicile \\
\hline Mobility & 0.029 & 0.056 \\
Self-Care & 0.590 & 0.006 \\
Usual Activities & 0.134 & 0.051 \\
Pain & 0.150 & 0.206 \\
Anxiety & 0.001 & 0.090 \\
Perception of Health Status & 0.000 & 0.346 \\
\hline
\end{tabular}

Table 7 shows that mobility dimensions, anxiety dimensions as well as perceptions of health status have differences in score based on participant level of education. In the self-care dimension also found differences in scores based on the participant's domicile.

\section{Discussion}

Based on the results of the correlation, it shows that the hypothesis in this study was accepted, there was a significant relationship between mindfulness and quality of life on pregnant women in Indonesia. The results of this study are also in line with previous research conducted in Indonesia (Fourianalistyawati, Listiyandini, and Fitriana, 2017)on the subject of adults showing a correlation between mindfulness and quality of life [19].

This result supports previous research that applied mindfulness-based interventions to reduce complaints experienced by pregnant women [3]. The mindfulness interventions given in previous studies show better quality of life than before intervention [20],[21]. The higher mindfulness possessed by someone can cause himto gain higher mindfulness as well as encourages him to increase the quality of life. Furthermore, mindfulness also shows an improvement in psychological stress, positive affect and overall health of pregnant women [20].

The results of this study indicate a significant relationship in the dimensions of acting with awareness and some dimensions on quality of life. Acting with awareness is how individuals are present and focused when performing an activity and not behaving automatically or directing a focus on something else [12]. Mindfulness helps people to focus and avoid positive or negative thoughts so they can understand what is happening in the present [22]. The more a person is present and the focus on what is being done then he has no problem in moving around like walking. In mindfulness-based interventions, there are related exercises running with conscious and focus.

In addition to mobility, the dimensions of acting with awareness also relate to the usual dimensions of activities, pain, and anxiety in quality of life. The more a person presents in every activity that is being done,the more she will be able to perform daily activities with more focus. Then the person also tends to feel pain, discomfort, and depression with anxiety 
will be lower. Also, a person can feel that he has better health or condition, if the dimension of acting with awareness is higher.

Non-judging dimensions are also found to be related to several dimensions in quality of life. Non-judging is how a person abstains from judging his thoughts and feelings [12]. The non-judging dimension has a negative relationship with the usual dimensions of activities, pain, and anxiety; and a positive relationship with perception of health status.

If the attitude to accept, open and compassion in mindfulness are applied by the pregnant women; then they can see the changes that occur within them as something that is not permanent and will pass. Pregnant women will have different concepts of their condition, such as having control over themselves, not easy to feel tired, happy or reduce physical pain. Thoseconcepts happen because pregnant women are more focused on the experience or the sensation they experienced without judging by using their thoughts or feelings [21]. So, the more a person accepts and does not judge against his or her thoughts and feelings, the lower the person's tendency to feel the discomfort/sickness and depression/anxiety.

The person also has a low tendency to the problem when performing daily activities. The low tendency to the problem can happen because the mindfulness helps pregnant women to regulate the negative emotions they experience. By applying non-judging to these negative emotions, expectant mothers can build better-coping skills and can reevaluate stressful factors [22]. Pregnant women become more adaptive in repressing a stressful experience [21]. With high non-judging too, a person's perception of her health condition is getting better.

In this study, it was also found the differences in scores on some dimensions of mindfulness-based on their marital status. Also, the quality of life also found differences in scores based on educational levels and also the participants' domicile.

\section{Conclusions}

It is concluded that there is a relationship between mindfulness and quality of life, especially in the dimensions of acting with awareness and non-judging of inner experience. These results are expected to be the basis of further research, to find the role of mindfulness techniques on improving the quality of life in pregnant women.

Acknowledgments. This research was conducted with funding support from internal research fund grant from YARSI University Jakarta.

\section{References}

[1]C. Venkata and S. B. Venkateshiah, "Sleep-Disordered Breathing During Pregnancy,” J Am Board Fam Med, vol. 22, no. 2, pp. 158-168, 2009.

[2]Y. Akhyar, "Deteksi Ibu Hamil Resiko Tinggi (Bumil Risti) Di Posyandu,” 2010.

[3]A. Hughes, M. Williams, N. Bardacke, L. G. Duncan, S. Dimidjian, and S. H. Goodman, "Mindfulness approaches to childbirth and parenting.," Br. J. midwifery, vol. 17, pp. 630-635, 2009.

[4]K. W. Brown and R. M. Ryan, "The benefits of being present: Mindfulness and its role in psychological well-being,” J. Pers. Soc. Psychol., vol. 84, no. 4, pp. 822-848, 2003.

[5]J. Kabat-Zinn, Full Catastrophe Living: Using the Wisdom of Your Body and Mind to Face Stress, Pain, and Illness. Delacorte Press, 2005.

[6]S. Jain et al., "A randomized controlled trial of mindfulness meditation versus relaxation training: Effects on distress, positive states of mind, rumination, and distraction," Ann. Behav. Med., vol. 33, no. 1, pp. 11-21, 2007. 
[7]C. Germer, The mindful path to self-compassion. 2009.

[8]J. Kabat-zinn, "Mindfulness-Based Interventions in Context: Past , Present, and Future," no. 2002, pp. 144-156, 2003.

[9]R. Harris, ACT Made Simple. Oakland: New Harbinger Publications, Inc., 2009.

[10]C. Mace, Mindfulness and Mental Health: Therapy, Theory and Science. 2008.

[11]E. Fourianalistyawati, "Mindfulness: Membawa Kesadaran sebagai Langkah Awal Memaknai Perjalanan Hidup," in Warna-warni Psikologi untuk Negeri: Pemikiran dan Aplikasinya, Tim Pengajar Fakultas Psikologi YARSI, Ed. Jakarta: Deepublish, 2017, pp. 23-30.

[12]R. A. Baer et al., "Construct validity of the five facet mindfulness questionnaire in meditating and nonmeditating samples," Assessment, vol. 15, no. 3, pp. 329-342, 2008.

[13]R. Renwick and I. Brown, Quality of Life, Health Promotion \& Rehabilitation. California: Sage Publication, Inc, 1996.

[14]N. Effendy, "Pengaruh Psikoterapi Transpersonal terhadap Kualitas Hidup Pasien HIV \& AIDS," Disertasi, 2008.

[15]B. J. Kemp, "Research Report: Maintaining Quality of Life." 2000.

[16]L. Hilderley, "Quality of Life.” 2001.

[17]V. Morrison and P. Bennett, An Introduction to Health Psychology. Edinburgh: Pearson Prentice Hall, 2006.

[18]F. D. Purba et al., "Quality of Life of the Indonesian General Population: Reliability and Population Norms of the EQ-5D-5L and WHOQOL-BREF," in ISPOR 7th Asia-Pasific Conference, 2016, pp. 1-17.

[19]E. Fourianalistyawati, R. A. Listiyandini, and T. S. Fitriana, "Hubungan Mindfulness dan Kualitas Hidup Orang Dewasa," in Prosiding Forum Ilmiah Psikologi Indonesian (FIPI). Fakultas Psikologi Universitas Tarumanegara. Diunduh dari researchgate. net pada, 2017, vol. 12.

[20]I. Nyklíček and K. F. Kuijpers, "Effects of mindfulness-based stress reduction intervention on psychological well-being and quality of life: Is increased mindfulness indeed the mechanism?," Ann. Behav. Med., vol. 35, no. 3, pp. 331-340, 2008.

[21]R. Yazdanimehr, A. Omidi, H. Akbari, and Z. Sadat, "Mindfulness Training and Quality of Life Among Pregnant Women: A Randomized Clinical Trial Mindfulness Training and Quality of Life Among Pregnant Women : A," Nurs Midwifery Stud, vol. 6, no. August 2016, pp. 1-8, 2016.

[22]E. Shahtaheri, S. Hosseinian, M. Ebrahimi, Z. Jalilabadi, and F. Mirderikvand, "The impact of stress reduction program based on mindfulness and conscious yoga on depression, perceived stress" Acta Medica Mediterr., vol. 32, no. July, pp. 2047-2050, 2016. 